\title{
Lesiones del himen en reconocimientos médico legales (RML) ginecológicos por delitos contra la libertad sexual
}

\author{
Ulises Mejía Rodríguez¹, Alex Mejía Rodríguez²
}

\section{RESUMEN}

Objetivo: Determinar las caracteristícas de las lesiones himeneales y lesiones genitales, paragenitales y extragenitales. Material y Métodos: Se realizó un estudio descriptivo prospectivo de enero a diciembre del 2013.

Resultados: Se realizaron 47 RML Ginecólogicos por delitos contra la libertad sexual. El 38,29\% (18/47) correspondio a peritadas entre 15 a 17 años. Los hallazgos fueron: himen Integro $(18,92 \%)$, himen complaciente $(8,11 \%)$, defloración reciente $(8,11 \%)$ y defloración antigua $(72,97 \%)$, entre otros hallazgos.

Conclusión: Las desfloraciones antiguas pueden tener lesiones himeneales nuevas, ello debido al diámetro del orificio himenal, existiendo mayor frecuencia cuando el orificio himenal es pequeño y mediano; a diferencia de cuando el orificio himeneal es grande o muy elástico (himen complaciente) que crea dificultades en el reconocimiento de lesiones. (Horiz Med 2014; 14(4): 24-30)

Palabras clave: Delitos contra la libertad sexual, himen, lesiones, desfloración reciente, desfloración antigua. (Fuente: DeCS BIREME).

Hymen injuries in medical legal recognition (MLR) for crimes against gynecological sexual freedom

\begin{abstract}
Objective: To determine hymenal injuries and genital, paragenital and extragenital lesions.

Material and Methods: A prospective descriptive study was conducted January to December 2013 .

Results: 47 MLR were performed gynecological for crimes against sexual freedom; $38.29 \%$ (18/47) corresponded to women between $15-17$ years. The findings were: Integro hymen $(18.92 \%)$, willing hymen $(8.11 \%)$, Recent deflowering $(8.11 \%)$ and old deflowering $(72.97 \%)$, among others findings.

Conclusion: Older Defloration hymens may have new lesions, this due to the diameter of the hymenal orifice, there most often when the hymenal orifice is small to medium; unlike when the hymen hole is large or very elastic we face a complacent hymen which creates difficulties in recognizing injuries. (Horiz Med 2014; 14(4): 24-30)
\end{abstract}

Key words: Crimes against sexual freedom, Hymen, injury, newly deflowering, old deflowering. (Source: MeSH NLM).

Médico Legista, Master en Medicina Forense, Doctorando en Criminalística. Insituto de Medicina Legal Perú.

Estudiante de Medicina Universidad Nacional Jorge Basadre - Tacna 


\section{INTRODUCCIÓN}

Los delitos contra la libertad sexual, son un problema relevante de salud pública. Definido por la OMS como el uso intensional de la fuerza de hecho o como amenaza contra uno mismo, otra persona o grupo o comunidad, que cause o tenga muchas probabilidades de causar lesiones, muerte, daños psicológicos, transtornos del desarrollo o privaciones (1).

Por otra parte, cuando se habla de delitos sexuales, se esta aludiendo a una categoria jurídico penal, ya que son actividades sexuales o vinculadas con lo sexual y que son delito en cuanto constituyen acciones u omisiones tipicas; es decir que estén previstos como delitos en una ley penal.

En este tipo de lesiones, el bien jurídico protegido por el derecho es la libertad sexual de las personas o bien la moralidad pública. Siendo, desde el punto de vista médico forense los delitos contra la libertad sexual los que presentan mayor interés por que afectan la libertad sexual y sobre todo por que presentan una característica común en las diferentes legislaciones, siendo ello la existencia de alguna clase de actividad sexual bajo alguna forma de violencia (2).

El Código Penal Peruano, establece que se comete un delito contra la libertad sexual cuando una persona con violencia o grave amenaza obliga a otra persona a tener acceso carnal por via vaginal, anal o bucal o realiza actos anàlogos, introduciendo obj etos por alguna de las dos primeras vìas; lo que ha creado la necesidad, entre médicos del Instituto de Medicina Legal del Perú, de una capacitación constante a fin de lograr el perfeccionamiento en el diagnóstico forense de las lesiones himeneales y anales, en delitos contra la libertad sexual.

Investigaciones científicas nacionales, han reportado: las diferentes características del himen, la importancia de presentar estadísticas reales y confiables para la aplicaciòn en el ámbito jurìdico (3), la importancia de conocer los criterios diagnòsticos ùtiles en la definiciòn de delitos contra la libertad sexual. Diversos estudios, han resaltado lo importante que resulta determinar las lesiones himeneales, ya que existen casos de confusiòn entre las ocacionadas sexualmente y las producidas por accidente al introducirse otros agentes (juguetes, manej ar bicicletas, etc).

Las definiciones jurídicas, implican la necesidad de difundir conocimientos médicos legales relacionados a la determinación de integridad sexual, sus concepciones forenses y sobre todo legales. Los conocimientos deben ser transmitidos a todo profecional de salud que evalúa a las personas denunciantes por delitos contra la libertad sexual. Todo médico, debe estar capacitado en la identificaciòn de lesiones himeneales, la que tendrá una trascendencia legal.

El objetivo del presente estudio fue determinar las lesiones himeneales en personas que han denunciado un delito contra la libertad sexual.

\section{MATERIAL Y MÉTODOS}

Estudio descriptivo prospectivo realizado en la División Médico Legal (DML) Chucuito, ubicada en la ciudad de Puno durante los meses de Enero a Diciembre 2013. Para el estudio se seleccionó las pericias médico legales de delitos contra la libertad sexual, las que fueron solicitadas por la PNP, Fiscalia y Juzgado.

Para proceder al examen médico legal ginecológico, a la toma de fotografias y de muestras para examen espermatológico, se solicitó autorización a través del formato de consentimiento informado a las personas examinadas; siendo asi y amparándonos en las consideraciones del acto médico y en el sigilio pericial, omitimos la identificaciòn de las peritadas.

Población de estudio: todas las peritadas que denunciaron delitos contra la libertad sexual y que acudieron a la DML I Chucuito, para un examen de reconocimiento médico legal ginecológico.

Se determinó y describió las lesiones y caracteristicas del himen; clasificando las lesiones de himen en desgarros recientes (menores de 10 dias de producido la lesión) o de desgarros antiguos 
(mayores a 10 dìas) (10).

Se consideró lesiones himeneales recientes en himenes con desfloración antigua (equimosis, tumefacción, laceración entre otras).

Al estudiar las caracteristicas del himen, se determinó que el himen complaciente o dilatable era aquel himen elástico o con elasticidad aumentada que presenta un diámetro transhimeneal mayor a $30 \mathrm{~mm}$. Ya que cifras inferiores a esa medida son consideradas normales (11).

En mujeres prepúberes el diámetro transhimeneal normal es de 4 a $15 \mathrm{~mm}$. Estos datos métricos fueron obtenidos de investigaciones realizadas en 1839 menores, segùn lo reportado en la literatura médica (12). Otros estudios han utilizado una medida de $10 \mathrm{~mm}$ como diámetro maximo normal (13 - 17). En el presente estudio, se consideró como valor máximo al diámetro transhimenal igual a 10,5 $\mathrm{mm}$, ello en ausencia de penetración (18).

Las evaluaciones ginecológicas las realizamos en presencia de personal femenino, ello para evitar discrepancias en cuanto a la intimidad de la peritada.

Se excluyó del estudio a 10 peritadas, de los cuales 2 no se presentaron al examen ginecológico y 4 no dieron el consentimiento para ser examinadas y 4 no culminaron el reconocimiento médico legal. Los datos fueron procesados en el programa Microsoft Exel 2013.

\section{RESULTADOS}

Se realizaron 1754 Reconocimientos Médicos Legales (RML); de los cuales 2,67\% (47/1754) fueron RML ginecológicos por delitos contra la libertad sexual, $24,12 \%(423 / 1754)$ por violencia familiar, $36,20 \%(635 / 1754)$ por lesiones, $0,11 \%(2 / 1754)$ por mordedura canina, $12,48 \%(219 / 1754)$ post facto, $2,05 \%(36 / 1754)$ por suceso de tránsito, $17,45 \%(306 / 1754)$ pericias de psicología forense y el $4,92 \%$ otros.

El mayor porcentaje de las peritadas tenían entre 15 a 17 años, 38,29\% (18/47), seguido de peritadas entre 18 a 60 años de edad con 27,66\% (13/47).
Figura 1

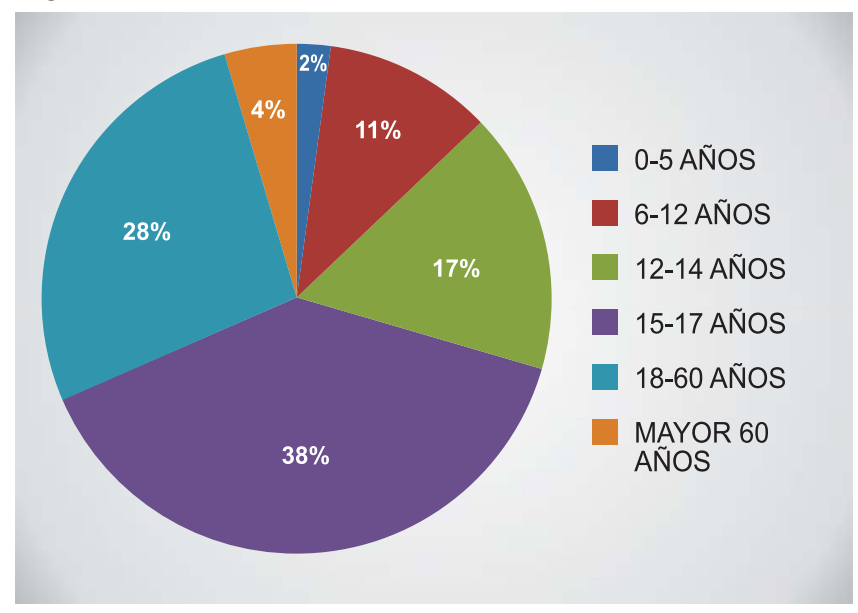

Figura 1.- Población de estudio según la edad; muj eres que solicitan RML por Delito contra la Libertad Sexual.

Ninguno de los denunciantes fue del sexo masculino.

De las personas que acudieron por un RML ginecológico: 10 no realizaron el RML Ginecológico; de ellas, 2 no se presentaron, 4 no firmaron el consentimiento informado y 4 no permitieron terminar con el RML; con lo que tuvimos, 37 peritadas como población total de estudio. Fig. 2

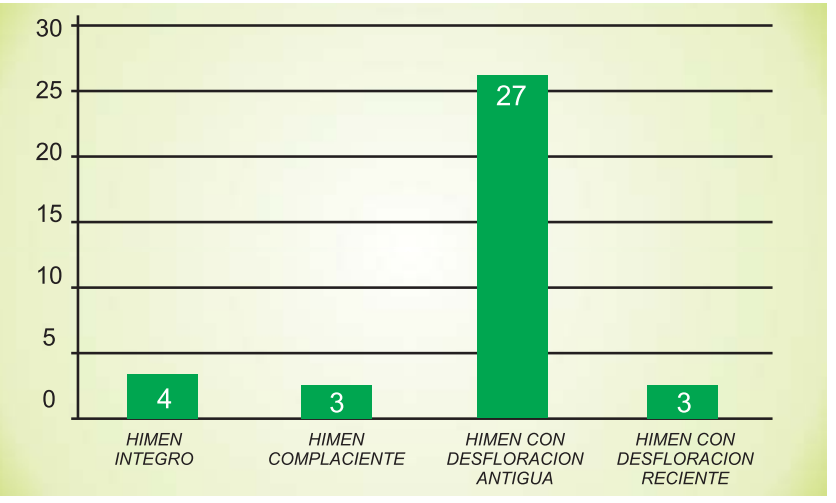

Figura 2.- Clasificación de himenes sin lesiones (integro, complaciente), y con lesiones (desfloración reciente y antigua), durante el RML ginecológico por delitos contra la libertad sexual.

El 18,92\% (7/37) presentaron himen íntegro o himen con bordes regulares que no presentan lesiones, con el borde interno que delimita el orificio que no presenta ninguna alteración en su morfología; de ellos, el $8,11 \%(3 / 37)$ presentaron himen complaciente o himen que presentaba un orificio amplio debido a que su elasticidad se encontraba 
aumentado (himen dilatable). Figuras 3 y 4.
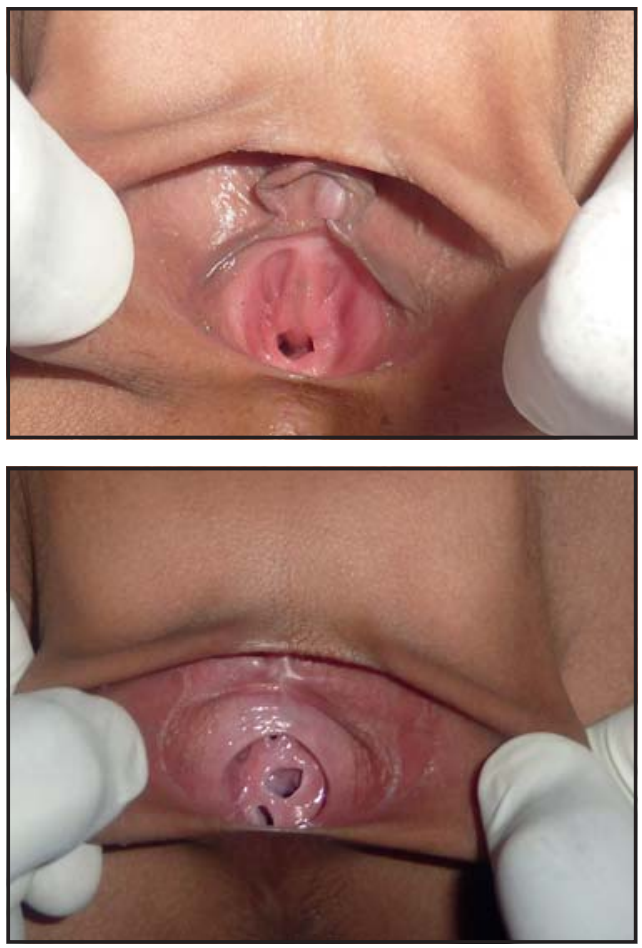

Figuras 3 y 4.- Himen integro o himen con bordes regulares que no presenta lesiones, con el borde interno que delimita el orificio.

Se evidenció desfloración en el 81\% (30/37), el $8,11 \%(3 / 37)$ presentaron desfloración reciente y el $72,97 \%$ (27/37) presentaron desfloración antigua.

El 62,16\% (23/37) presentó lesiones himeneales; siendo clasificados de acuerdo a las características macroscópicas en lesiones recientes (dentro de los 10 días de producida la lesión) y en lesiones antiguas (más de 10 días). Figuras 5 y 6.

Las desfloraciones antiguas representaron el $72,97 \%$ (27/37), de ellos; los desgarros himenales antiguos, con lesiones recientes, el 54,05\%(20/37) y las desfloraciones recientes (desgarro himeneal reciente) representaron el $8,11 \%(3 / 37)$.

Se observó que $62,16 \%(23 / 37)$ presentaron lesiones himeneales, de ellos 48,65\% (18/37) tuvieron otras lesiones concomitantes, lo que se expresó: el $18,92 \%(7 / 37)$ presentaron otras lesiones genitales, el $13,51 \%(5 / 37)$ pesentaron lesiones paragenitales y el $16,22 \% \quad(6 / 37)$ presentaron lesiones extragenitales. Figuras 7 y 8 .

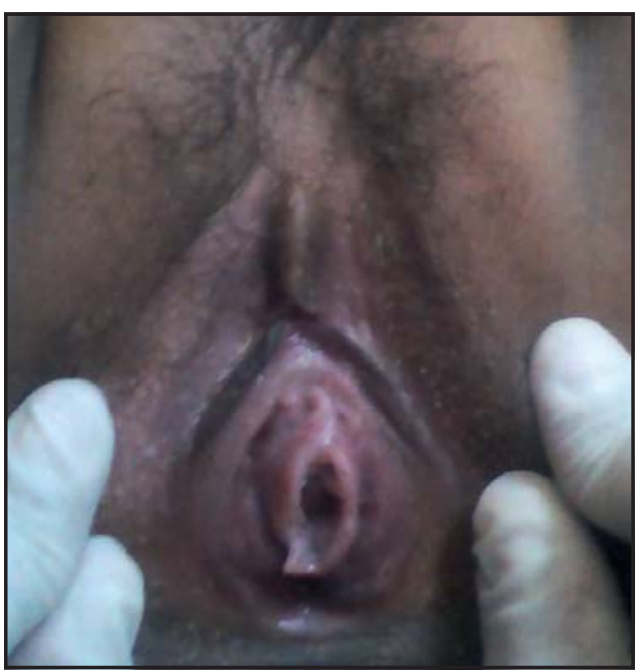

Figura 5.- Desfloración reciente, nótese himen con solución de continuidad en el ancho himeneal, el cual se denomina desgarro, que se acompaña de signos vitales peri lesionales: sangrado, equimosis, congestión, eritema, edema, tumefacción.

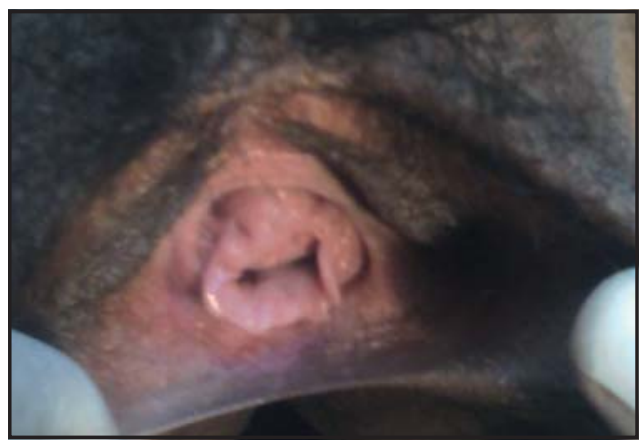

Figura 6.- Desfloración antigua, himen con lesiones cicatrizadas o ya resueltas, no presenta signos vitales perilesionales himenales.

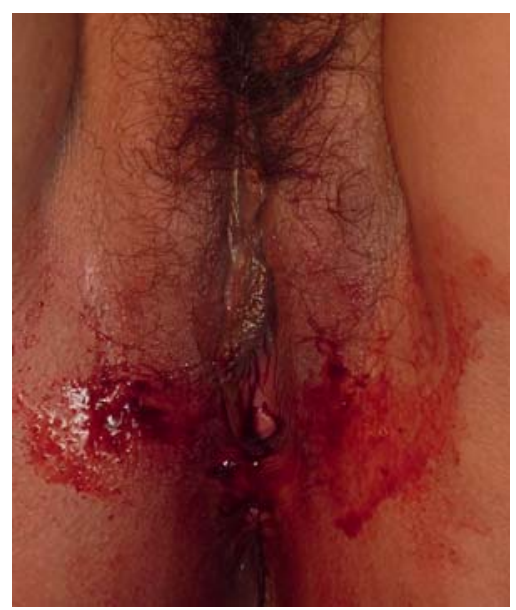

Figura 7.- Lesiones en área Genital, localizadas en el área genital o ano genital como son genitales externos, periné y ano. 


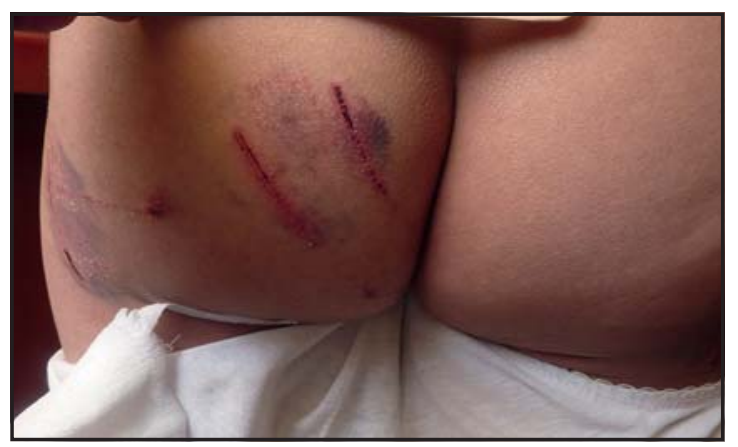

Figura 8.- Lesiones en área Paragenital, son lesiones localizadas en la superficie interna de los muslos, nalgas, pubis e hipogastrio.

\section{DISCUSIÓN}

El RML ginecológico ó exámen médico legal ginecológico, es un procedimiento que constituye el acto médico y es una prueba para resolver un problema jurídico. Lo que persigue la justicia es conocer la verdad de lo sucedido o de la prueba, por ello; es de gran importancia para los operadores de justicia: Fiscalía y Poder judicial.

El estudio médico forense de las victimas reales o presuntas de agresiones sexuales, es una tarea difícil y compleja, donde resulta particularmente necesaria la unión de la formación teórica con la experiencia práctica. La evaluación, se plasma en un informe médico denominado Reconocimiento Médico Legal Ginecológico, el cual, tiene por objetivo básico la peritación médico forense en los delitos contra la libertad sexual, que consiste en demostrar la existencia de: actividad sexual y/o violencia.

El RML debe ser redactado técnica y científicamente, de acuerdo al exámen solicitado por la autoridad competente. Ante un delito contra la libertad sexual, la autoridad competente designará al profesional responsable de la evaluación clínica de la persona denunciante, el juez nombra de preferencia a especialistas que se encuentren sirviendo al Estado (21).

Se emplearán todos los medios científicos y técnicos que fuesen posibles (22), debiendo el profesional que evalúa, obtener toda evidencia que se relacione con el delito (vellos púbicos, vaginales $\mathrm{y} / \mathrm{o}$ anal, etc. ).
Las investigaciones han determinado la utilidad de recojo de evidencias de interés forense hasta 44 horas después del acto sexual (23).

Un exámen médico legal, siempre será practicado, previo consentimiento de la víctima, exclusivamente por el médico encargado del servicio, con la asistencia de un profesional auxiliar. Asimismo, se permite la presencia de otras personas, previo consentimiento de la víctima (25).

Hay que tener presente, que el himen cambia con la edad y en respuesta a las influencias hormonales.

El orificio himenal o introito vaginal, presenta diámetros variables: $<1.0 \mathrm{~cm}$ hablamos de un orificio himeneal pequeño; entre 1.0 y $2.0 \mathrm{~cm}$, orificio himeneal mediano; > $2.0 \mathrm{~cm}$ orificio himeneal grande; entre 2.5 y $3.0 \mathrm{~cm}$ himen dilatable o himen complaciente.

Los hallazgos himeneales descritos durante nuestra evaluación se relacionaron con signos de lesiones tráumaticas a nivel genital. Siendo el pene, los dedos u otros objetos duros de superficie roma, agentes clasificados como contundentes (lesiones denominadas contusas) (26).

Las lesiones del himen relacionadas a un abuso sexual, serán identificadas y evidenciadas como desgarrosó laceraciones, equimosis y tumefacciones del borde himeneal.

La mayoría de peritadas, estuvo en el rango de 15-17 años de edad. Nuestros datos también se relacionan con estudios nacionales publicados por Pacheco, donde las victimas fueron menores, entre 6-17 años de edad; como en otros estudios.

Nuestros hallazgos muestran que es posible determinar lesiones recientes sobre desgarros himeneales antiguos, los cuales constituyen lesiones himeneales antiguas con lesiones himeneales recientes concomitantes, ello debido a que mujeres que presentaron desgarros antiguos presentaron un orificio himeneal pequeño o mediano, tal como lo describe la literatura sobre diametros en orificios himeneales.

Un porcentaje de lesiones observados presentaron un orificio himeneal entre 2.5 y 3.0 o mayor 
de diámetro, lo que denominamos himenes complaciente, siendo las caracteristicas de este himen, que tiene la propiedad de ser muy elástica y presenta un orificio muy amplio, creando dificultad al profesional que no tiene experiencia en reconocer la existencia de lesiones recientes. El encontrar un himen complaciente en un RML Ginecológico, no niega la introducción del pene u otro miembro del cuerpo u objeto.

Actualmente, los médicos, experimentan un temor cuando no están capacitados en identificar lesiones himeneales y plantean erróneamente el diagnóstico de himen complaciente, con el fin de evitar problemas futuros con implicancias médico legales.

Los RML que determinan las lesiones himeneales son muy útiles en la tipificación del delito contra la libertad sexual; por lo tanto, se tiene que tener mucho cuidado ya que el RML ginecológico debe de guardar relación de asociación entre lo descrito en el cuerpo del RML (data y examen fisico) con las conclusiones emitidas, por que de no ser asi podria ser el inicio para un futuro caso de archivo de algun delito contra la libertad sexual.

Entonces, podemos afirmar la importancia de la Médicina Legal como la ciencia que está científicamente avanzando, que enseña las diferentes variantes himeneales y sus lesiones haciendo que los médicos forenses tengan el suficente criterio técnico y científico al momento de acreditar sus hallazgos.

\section{Fuentes de financiamiento}

El estudio ha sido autofinanciado por el autor.

\section{Conflicto de interés}

El autor declara no tener ningún conflicto de interés.

\section{REFERENCIAS BIBLIOGRÁFICAS}

1. American Academy of Pediatrics Committee on Child Abuse and Neglect. Guidelines for the Evaluation of Sexual Abuse of Children: Subject Review (RE9819). Pediatrics 1999; 103 (1): 186-191.

2. Bauer $M$, Patzelt $D$ Protamine mRNA as molecular marker for spermatozoa in semen stains. Int J Legal Med 2003; 117(3),113116.

3. Bonnet EPF "Medicina Legal y Toxicología". Buenos Aires: Libreros, 1980.

4. Burgess AW, Holmstrom LL. Rape trauma syndrome. Am Journal of Psychiatry 1974; 131:981- 986.

5. Código penal. Delitos contra la libertad sexual.

6. Collins KA, Bennett A Persistence of Spermatozoa and Prostatic Acid Phosp-hatase in Specimens From Deceased Individuals During Varied Postmortem In-tervals. Am J Forensic Med Pathol 2001; 22 (3): 228-232.

7. Di Maio JM, Dana SE Homicidios relacionados con el sexo. En: Manual de patología forense. Ed. Díaz Santos, Madrid, 2003: 165167.

8. Di Nunno N, Melato M, Vimercati A, Di Nunno C, Costantinides F, Vecchiotti C, Frezzini C, Cina S, Vimercati F. DNA identification of sperm cells collected and sorted by flow cytometry. Am J Forensic Med Pathol 2003, 24 (3): 254-270.

9. Ernst AA, Green E, Ferguson MT, Weiss SJ, Green WM. The utility of anoscopy and colposcopy in the evaluation of male sexual assault victims. Ann Emerg Med 2000; 5:432-7.

10. Gayet J, “Manual de la Policía Científica”. España: Zeus, 1965.

11. Calabuig G, Villanueva E. Delitos contra la libertad sexual. Medicina Legal y Toxicología. $5^{a}$ Ed. Masson, Barcelona, 1998: 495514.

12. Glasser D, Stephen F. Abuso sexual en niños. Ed. Paidós, Buenos Aires, 1997.

13. Guzmán C. "Manual de Criminalística", Ediciones LA ROCA, $1^{\text {a }}$ edición, Buenos Aires-Argentina, 2000, p. 487.

14. Gray-Eurom K, Seaberg DC, Wears RL. The prosecution of sexual assault ca-ses: correlation with forensic evidence. Ann Emerg Med. 2002; 39(1):39-46.

15. Grossin C, Sibille I, Lorin de la Grandmaison G, Banasr A, Brion F, Durigon M Analysis of 418 cases of sexual assault. Forensic Sci Int 2003; 131 (2-3):125-130.

16. Heger AH, Ticson L, Guerra L, Lister J, Zaragoza T, McConnell $G$, Morahan M. Appearance of the genitalia in girls selected for nonabuse: review of hymenal morphology and nonspecific findings. J Pediatr Adolesc Gynecol. 2002 Feb;15(1):27-35.

17. Knight B. Delitos sexuales. En su: Medicina Forense de Simpson. Ed. El Manual Moderno, México, 1994: 231-245.

18. Kvitko LA. La violación. Peritación medicolegal en las presuntas víctimas del delito. 2a edición. México: Trillas 1995. 
19. Sosa M, Juventino. Criminalística. México D.F.: Limusa, 2002. T. 1. p. 49.

20. Moreno R. "Manual de Introducción a La Criminalística", Editorial Porrúa S. A., México, 1990, p. 233.

21. Vanrell P. Violencia sexual. En su: Sexología forense. Editora Unimontes, Mon-tes Claros, 2001: 291-394.

22. Policía Nacional del Perú: “Manual de Criminalística”, Servicios Gráficos JMD, Lima-Perú, 2006, p. 232.

23. Rodríguez H. Abuso sexual en niños: enfoque médico-legal. En Baráibar R (Co-ord.) La salud en la infancia y la adolescencia. Ed. Arena, Montevideo, 1999: 141-149.

24. Simonin C. Medicina Legal Judicial. Barcelona: Jims. 1962.

25. Vargas Alvardo E. Medicina Forense y Deontologia Medica "da edicio. Exico: Editorial Trillas; 1999.

26. Zajaczkowski R. "Manual de Criminalística", Ediciones Ciudad Argentina, Bs. Aires-Argentina, 1998, p. 260.

\section{Agradecimiento}

A todas las personas que me rodean, por su colaboración y apoyo constante.

\section{Correspondencia:}

Ulises Mejía Rodriguez

Dirección: División médico legal - Chucuito. Puno Teléfono: 942-161374

Correo electrónico:

ulisesmej iarodriguez@hotmail.com
Recibido: 24 de Julio de 2014

Aprobado: 13 de Octubre de 2014

\section{HORIZONTE MÉDICO}

Indizada a: Scielo, Latindex, DOAJ , entre otras

Difundiendo la investigación, más allá; de nuestras fronteras

Se distribuye gratuitamente y por canje.

Está disponible a texto íntegro en el siguiente

e-mail: horizonte_medico@usmp.pe y

en la web:

www. medicina. usmp. edu. pe/ horizonte/ principal. php

\section{Siguenos en:}

Revista Horizonte Médico FMH USMP

@HorizMed

facebook

twittery 